\title{
scripted
}

Volume 13, Issue 2, August 2016

\section{CONFERENCE REPORT: 13TH WORLD CONGRESS OF THE INTERNATIONAL ASSOCIATION OF BIOETHICS, EDINBURGH 14-17 JUNE 2016 (IAB2016)}

Edward S. Dove ${ }^{1}$ Isabel Fletcher ${ }^{2}$, Agomoni Ganguli Mitra ${ }^{3}$, Graeme Laurie ${ }^{4}$, Catriona McMillan ${ }^{5}$, Nayha Sethi ${ }^{6}$, Annie Sorbie and Samuel Taylor-Alexander $^{8^{*}}$

\begin{abstract}
In this Conference Report, we present a summary of the key highlights and themes of the 13th World Congress of the International Association of Bioethics, which took place in Edinburgh, Scotland 14-17 June 2016 (IAB2016).
\end{abstract}

DOI: $10.2966 /$ scrip.130216.202

\section{cc) () $९$}

EY NG ND (C) Edward S. Dove, Isabel Fletcher, Agomoni Ganguli Mitra, Graeme Laurie, Catriona McMillan, Nayha Sethi, Annie Sorbie and Samuel Taylor-Alexander 2016. This work is licensed under a Creative Commons Licence. Please click on the link to read the terms and conditions.

\footnotetext{
${ }^{1}$ PhD Candidate and Member of Liminal Spaces Project, School of Law, University of Edinburgh.

${ }^{2}$ Senior Research Fellow in Medical Sociology in Liminal Spaces Project, School of Law, University of Edinburgh.

${ }^{3}$ Research Associate in Liminal Spaces Project, School of Law, University of Edinburgh.

${ }^{4}$ Professor of Medical Jurisprudence and PI of Liminal Spaces Project, School of Law, University of Edinburgh.

${ }^{5} \mathrm{PhD}$ Candidate and Member of Liminal Spaces Project, School of Law, University of Edinburgh.

${ }^{6}$ Research Associate in Socio-legal Studies in Liminal Spaces Project, School of Law, University of Edinburgh.

${ }^{7} \mathrm{PhD}$ Candidate and Member of Liminal Spaces Project, School of Law, University of Edinburgh.

8 Senior Research Fellow in Medical Anthropology in Liminal Spaces Project, School of Law, University of Edinburgh.

* All authors contributed equally to this Conference Report.
} 


\section{Introduction}

For the first time since 2000, the World Congress of the International Association of Bioethics (IAB) returned to the United Kingdom. This year, the Scots hosted the world's largest gathering of bioethicists at the Edinburgh Congress, welcoming over 700 delegates from 44 countries. In addition to the typical academic focus of such meetings, IAB2016 offered dedicated programmes on Arts+Ethics and for Early Career Researchers (ECRs). We members of the Liminal Spaces Project, ${ }^{2}$ hosted by Edinburgh Law School and funded by the Wellcome Trust, were present for the duration of the Congress. In this Conference Report, we offer an account of some of the key highlights and themes.

\section{Key Highlights and Themes}

\subsection{Aesthetics}

Aesthetics is understood to influence how we make sense of and construct our worlds. Social scientists and humanities scholars examine the social dimensions of taste whether in making sense of why we prefer a particular musical genre or in examining ideas of beauty - and the ways in which notions of what counts as "good" circulate within the domain of aesthetics. It is fitting, therefore, that aesthetics was a central theme at the Congress, both inside and outside of the Art+Ethics stream. In their keynote speeches, Paul Macneil (University of Sydney) discussed the centrality of the arts to understandings of bioethics, and Catherine Belling (Northwestern University) movingly described the impact of anaesthetic disruption on patients' memories and personal narratives.

A number of exhibitions and performances, organised by the Arts+Ethics Research Group, provided delegates with the opportunity to think about the centrality of form in medicine and meditate on non-verbal ways to represent health, ethics, pathology, and power. In Vishal Shah's poignant sound sculpture, "Velum," photographed skin was fed through a computer algorithm and visualised on screen, contorting with the music of an exuberantly played double bass. Irish artist Louise O'Boyle displayed materials in scientific vessels, raising questions about ownership of human body parts. Bela Fishbyn's photograph, "Tatar Couple," captured health, ethics, and care in a simple, gripping image of an elderly couple being still with each other in their home. These and the eleven other still pieces moved the everyday into ethics and ethics into the everyday, challenging our common understandings of care, ownership, biology, and data.

The centrality of aesthetics to ethical considerations also featured in many of the panel and symposia discussions. Speakers brought to the fore how regulatory commitments are mediated by the approach we take to understanding the human self and illness. The questions "What is human?" and "What is normal?" circulated through panels on topics as diverse as enhancement, relational ethics, and vulnerability. A Nuffield Council on Bioethics symposium, "Ethics and Regulation of

\footnotetext{
${ }^{2}$ Liminal Spaces Project, available at http://www.liminalspaces.ed.ac.uk/ (accessed 10 Aug 16).
} 
Global Beauty Practices and Procedures," generated lively conversation on the need to govern globalised cosmetic interventions. In a parallel session on "Vulnerability, Treatment and Relationships," Karin Jongsma (UMC Gottingen) analysed patient groups, demonstrating profound differences between how the needs of individuals are represented depending on whether a group is constituted of, or for, people with a disease such as autism. Examining breast screening programs, Harold Schmidt (University of Pennsylvania) showed the diversity of images and approaches used to persuade women to undergo testing. His analysis revealed how the number of "lifesaving" procedures is often measured through interventions, rather than actual detection and treatment of breast cancer. Finally, in a panel on Science and Technology Studies (STS) and bioethics, organised by Catherine Heeney (University of Edinburgh), speakers reflected on how facts and values become entwined, and particuarly how representations of biology dovetail with normative commitments in science and medicine.

\subsection{Early Career Researchers}

In recognition of the importance of supporting ECRs, IAB2016 offered a dedicated series of events tailored towards more junior delegates. The ECR thread included a session where three keynote speakers (Alastair Campbell, Sarah Chan, and Anant Bhan) each offered distinctive reflections on careers in bioethics. Campbell laid out the changing landscape of bioethics, which he has observed throughout his career. Bhan considered the various ways in which we can contribute to bioethics and related fields through advocacy, as well by traditional academic means. Chan comforted those of us who might suffer from existential angst about self-identifying as "bioethicists," encouraging us to think beyond pre-existing approaches and to be more critical of received narratives of science and medicine.

In addition to the keynote, three ECR Master Classes were held on (i) oral presentations, (ii) publications, and (iii) funding, policy, and career advancement. Each of these sessions featured experienced senior scholars recognised for their communication skills and achievements. In the master class on oral presentations, delegates were treated to presentions from Florencia Luna (FLACSO, Argentina) Muireann Quigley (Newcastle University), Inez de Beaufort (Erasmus Medical Centre for Rotterdam), and Julien Savulescu (Uehiro Centre for Practical Ethics, Oxford).

In the session on publications, Heather Widdows (University of Birmingham) discussed the importance of publication planning for one's academic career, including what and when (and when not) to publish and for what reasons. In addition to stressing that not all publications are equal - and, therefore, encouraging ECRs to put the most energy into research-focused publications that advance their field Widdows' advised ECRs ultimately to "just do it": to plan, prioritise, and produce publications throughout their careers. Dominic Wilkinson (Uehiro Centre for Practical Ethics, University of Oxford and editor of the Journal of Medical Ethics) described how editors make decisions about papers to send for review, how they select reviewers, and how they make decisions on which papers to accept. Wilkinson noted that there are three crucial stages for every author to consider: (i) getting the paper past the editor's initial triaging process for deciding whether it is interesting, novel, and of relevance to the field; (ii) getting it through the peer review process; and (iii) getting it to acceptance and publication. Many ECRs in the audience appreciated 
Wilkinson's inside knowledge of the editorial process and his frank discussion of the "tricks of the trade." Finally, Graeme Laurie (University of Edinburgh) presented on monographs, drawing on his experiences as joint editor of Cambridge University Press's Bioethics and Law series. Laurie advised ECRs on what a commissioning editor looks for - e.g. whether there is a market for the book proposal, especially in America - what raises red flags, and how to pitch successfully to an editor. He encouraged ECRs to think about the originality, significance, and rigour of their work. He also offered tips on improving a book proposal, as well as potential publishing strategies for ECRs, and thoughts on the challenges of publishing multi- versus interdisciplinary pieces. All three presenters emphasised the crucial need for the ECR to find their "research voice" and produce research-focused, high quality publications.

Panel members for the Funding, Policy and Careers Master Class were Hugh Whittall (Nuffield Council on Bioethics), Ilina Singh (Oxford Centre for Neuroethics), Dan O'Connor (Wellcome Trust), and Nils Hoppe (CELLS, University of Hannover). Whittall offered insights into working on policy issues, suggesting that, in order to effectively influence policy, it is crucial to identify key issues in a timely manner and understand when action can be taken. Singh encouraged us to present and advocate for our research as often as possible, and to appreciate that "impact" can often take time and occur further downstream from the research itself. She also highlighted the use of social media as a powerful tool for the dissemination of work. O'Connor offered entertaining and valuable instruction from a funder's perspective. $\mathrm{He}$ suggested that career narratives should be structured around creating a brand, value, and story, and that attractive funding applications always communicate how the funders' agenda is advanced through the applicants work, and repeatedly refer back to this point. Finally, Hoppe encouraged us to snap up opportunities to present our work, to network, to contribute to our communities, to collaborate beyond our own disciplines, and to take risks.

\subsection{HeLa}

The internationally acclaimed and award-winning theatre production of HeLa was much anticipated after an intense opening day of plenary and parallel sessions. Adura Onashile's electric performance told the story of the life and death of Henrietta Lacks and the HeLa cell line, which originated from a cancerous tumour biopsy taken from Lacks shortly before her untimely death in 1951, and which was used without her consent. Based on Rebecca Skloot's praised book, The Immortal Life of Henrietta Lacks, ${ }^{3}$ Onashile brought Lacks to life, as well as sensitively portraying her family and the part they played in seeking recognition for their mother's significant but unknowing contribution to science. As Onashile marked up the names of the men who had been recognised for their work on the HeLa cell line, and the scientific advances that had resulted, this served to starkly illustrate the absence of the woman who had made this work possible. Changing pace with ease, she captured Lacks' energy in life, as well as her deep love for the young family that she left behind. The audience were brought to their feet by the emotional breadth of Onashile's performance.

\footnotetext{
${ }^{3}$ Rebecca Skloot, The Immortal Life of Henrietta Lacks (New York: Crown, 2010).
} 
In the question-and-answer session that followed the performance, IAB delegates sought to understand what had motivated Onashile to tackle Skloot's text. Her answer was simple: "anger," coupled with a desire to promote the contribution that Lacks had made, in accordance with her family's wishes. In this vein, delegates probed the extent to which the Lacks family had consented to the performance. Onashile confirmed that she had contacted the family to seek and obtain their agreement. Delegates who teach the book to students highlighted the ongoing relevance of interwoven strands contained within the HeLa story - of poverty, racism, and injustice - in the context of the use of human tissue without consent for scientific endeavour and ultimately financial profit.

\subsection{Public Interest, Public Engagement, and Public Good}

At the heart of the HeLa production was a consideration central to the public interest strand of IAB2016 - the interplay between autonomy and the rights of the individual, on one hand, and the wider public interest(s) or public benefit(s) on the other. There was a clear appetite amongst those presenting and attending IAB2016 to scrutinise how public interests are understood, articulated, framed, and implemented in a range of contexts. Three cross-cutting themes emerged at the Congress from this multidisciplinary examination of the public interest: 1) the framing of the approach to the public interest; 2) public engagement and the role of empirical research in better understanding public interest; and 3) the operationalisation of the public interest.

Speakers at the Wellcome Trust-sponsored Liminal Spaces Project symposium, "What Does It Mean to Regulate in the Public Interest?", described challenges in the definition, scope, and implementation of the public interest in a rich, crossdisciplinary consideration that drew on philosophy, law, and the humanities. Leslie Stevens (University of Edinburgh) set the scene, proposing the adoption of a public interest mandate in order to refocus attention onto the public nature of administrative data, and to inform how public authorities value, and act upon, the data they hold. In doing so, she clearly drew out how the public interest could be used to address the barriers to data sharing identified in her work. David Townend (Maastricht University) focussed on the relationship between personal responsibility and the public interest, examining the extent to which the primacy given to autonomy places the notion of the public interest at odds with expectations of privacy. Alongside this, Alena Buyx (University of Kiel) considered the concept of solidarity in examining what it means to regulate in the public interest, highlighting the extent to which these concepts do and do not overlap, and thus whether and how the interests and rights of individuals can be compatible with notions of public interest. Annette Rid (King's College London) also sought to reframe the debate around health research regulation, drawing on a proportionate governance model to argue that protecting the interests of research participants is an essential part of regulating health research in the public interest. Finally, Mark Taylor (University of Sheffield) unpacked the concept of the public interest in the context of the use of patient confidential data for public policy objectives. In doing so, he emphasised that the public interest is not something to be balanced against privacy; instead, each can place limits upon the other because each should be accounted for in a conception of the other. Taylor's touchstone here was a recognition of the need for legitimacy: what can publics reasonably expect will happen with their data and which is in the public interest? 
Public engagement was a thread that ran through these discussions of public interest. In the "Health Research Consortia" parallel session, Sarah Cunningham-Burley (University of Edinburgh) considered public good arguments in the context of the use of linked data for research purposes. She drew on evidence from a range of public engagement activities to identify the multiple meanings of public good and researching in the public interest, and how these might be deployed in future governance structures. In particular, she highlighted how public benefit can be perceived and conceptualised in different ways - both by researchers and by publics and cautioned against top-down approaches that might limit debate. At the Farr Institute-sponsored symposium, "Governance Interoperability in Health Research Regulation," speakers built on this empirical theme, further examining the patient experience and the interface between patients and practitioners. Nathan Lea (University College London) focussed on the expectations formed by patients and practitioners as information is shared and reused beyond the therapeutic context. Adrian Thorogood (McGill University) presented the work of the Global Alliance for Genomics and Health in promoting effective and responsible sharing of genomic and health-related data. Leslie Stevens (University of Edinburgh) presented on the persistent cultural, sectoral, and technical barriers to sharing data across sectors in the UK. Finally, Don Willison (University of Toronto) presented data on patients' perspectives on appropriate flows of information.

In the final keynote address of the Congress, Baroness Onora O'Neill (University of Cambridge) addressed the topic of "Public Goods and Private Data." True to form, O'Neill offered a biting critique of the terms of the forthcoming European General Data Protection Regulation, arguing that its focus on content - the illusive construct of "personal data" - rather than on acts or behaviours that impact on citizens" privacy - is a failure of law both to capture and regulate what is important about privacy and also to deliver effective and responsible data sharing in the name of the public good.

\subsection{Justice and Global Bioethics}

There was a time in bioethics when the concept of justice was often confined to questions associated with resource allocation. Typically this was framed as the right to health (care), resource allocation, or priority setting in health care on the one hand, and on the other hand, considerations of fairness in the selection of research participants, standard of care during trials, and post-trial access to new drugs and therapy. While broader considerations informed and structured each of these debates, IAB2016 was a testimony to how bioethics, both local and global, is increasingly attuned to deeper and richer considerations of justice, including relational and structural aspects, and concerns beyond states and borders.

The two FAB ${ }^{4}$-IAB crossover keynote addresses by Lisa Eckenwiler (George Mason University) and Florencia Luna (FLACSO, Buenos Aires) established the significance of this topic. Eckenwiler illustrated the importance of place in considerations of justice in public health, describing it as a crucial aspect of the social determinants of health. She called for a bio-centred egalitarianism that would recognise the importance of ethical-placemaking for humans and their environment. With further

\footnotetext{
${ }^{4}$ Feminist Approaches to Bioethics, available at http://fabnet.org/ (accessed 10 Aug 16).
} 
attention to structural justice, Luna brought a gender lens to Zika as a public health and humanitarian crisis. Showing how women are disproportionately and unjustly affected both by the consequences of the disease and the policies surrounding it, Luna called for public health to be a voice of social conscience, setting the framework for empowerment.

Thus, both the global nature of bioethics and its close links to considerations of justice, understood broadly, were set out early in the Congress. This theme was then developed in further keynote addresses. Gillian Brock (University of Auckland) shared her expertise on the global medical brain drain, evaluating the practical steps low-income countries could take to retain medical skills within their borders, and so establishing a platform for discussing rights and obligations from the perspective of countries that otherwise tend to be on the receiving end of global justice perspectives. Echoing the need to incorporate the voice(s) of the Global South, Ashok Acharya (University of Delhi) problematised some of the assumptions often underlying the Global North-Global South divide. Finally, sociologist Alondra Nelson's (Columbia University) presentation on her qualitative research of genetic ancestry in the USA revealed how genomic testing intersects with personal histories and legal claims in novel ways. Her African-American interlocutors engage with ancestry testing to both produce knowledge about themselves and to sue persons that engaged in the transatlantic slave trade. The legitimacy of ancestry genetics, therefore, appears to be established more by courts than by genetic experts.

Several of the parallel sessions also highlighted the various tensions in global justice and global bioethics. For example, in an inspiring session exploring these tensions, "Problematizing Assumptions Underlying the 'Global South-Global North' Geographical Imaginary," several scholars illustrated the problems associated with seeming neutral terms such as "collaboration" or "capacity-building," using English as the default language in policy documents (rendering terms and concepts resistant to adequate translation on the ground), and the need for equalising partnerships. Finally, just prior to a handover session to the next IAB organisers (IAB2018 in New Delhi, India) - which is aptly titled, "Health for All in an Unequal World" - IAB President Angela Ballantyne (University of Otago) once again highlighted considerations of justice in global health when presenting on the ethical and fairness aspects of surrogacy in India.

\subsection{New Reproductive Frontiers}

Throughout IAB2016, the variety of bioethical issues associated with advances in technological, ethical, and philosophical approaches to reproduction resonated strongly. There were several sessions on mitochondrial donation (MD), artificial gametes, ectogenesis, abortion rights and ethics, conscientious objection, and crossborder commercial surrogacy. The presentations and discussions on reproductive technologies provided original and thought-provoking analysis.

In the symposium on "Ethical Questions in Mitochondrial Donation", Reuven Brandt and Stephen Wilkinson (both of Lancaster University), Ainsley Newson (University of Sydney), and Colin Gavaghan (University of Otago) explored the ethical and philosophical questions raised by this new technology, namely: personal identity and the right to know; the appropriate role of public consultation; the nature of the 
relationship between donors and resulting children; and the extent of the normative weight that we should apply to "parental preferences" in this context. Their presentations highlighted that while mitochondrial donation may be beneficial, the debates resulting from regulation of this technology in the UK leave much to be desired. The later symposium on "UK Mitochondrial Research and Legislation: Cutting Edge or Out on a Limb?" continued in this vein, providing stimulating analysis of the challenges and opportunities in the regulations, and salient questions about the UK's legislative motive for this. In a series of complementary talks, Erica Haimes and Ken Taylor (both of Newcastle University) criticised the current UK debates for their lack of nuance and questioned the depth and rigor of prior debates. Meanwhile, Cathy Herbrand (DeMontfort University) discussed the practical limitations of this regulatory attempt to "eradicate" mitochondrial disease. IIke Turkmendag (Sheffield University) highlighted the implicit significance of donated genetic material in these debates and provided a persuasive case for a different legislative conception of access to mitochondrial donors' identifiable information. Finally, Annelien Bredenoord (UMC Utrecht) described the importance of context in "copying-and-pasting" the UK's legislative answer to the US. Both symposia explored this topical area in an innovative manner, providing new challenges to a debate that has seemingly been put to rest by many, and adding much needed analysis to the quiet that has ensued since the UK's regulations came into force.

Parallels may be drawn with the symposium on "The Ethics of Human 'Artificial Gametes," which persuasively tackled a controversial area from varied angles, tying together new social considerations, such as reproduction for new forms of family, with the old, including genetic parenthood. John Appleby (King's College London) recommended that enrolment in clinical trials should be mandatory for the first parents of artificial gametes in order to benefit the ethical interests of parents, children, families, clinicians, researchers, and also society. Daniela Cutas (King's College London) reviewed the ethics of "solo" human reproduction, claiming that there are convincing arguments for pursuing research that enables solo reproduction. César Palacios-González (Umeå University) argued that in-vitro gametogenesis undermines the arguments against same-sex marriage advanced by the "new natural lawyers." Finally, Heidi Mertes (Ghent University) considered the ethical issues of deriving gametes from embryos created through fertilisation, arguing that a good reason for pursuing this research is that it might enable mutual genetic parenthood for same-sex couples.

\section{Conclusion}

The overarching question for the IAB2016 World Congress was: "What is the contribution of bioethics?" The Congress's focus on individuals, public interests, and public goods delivered a programme comprising over 70 parallel sessions, with almost 250 speakers addressing this crucial question in myriad forms. The enduring legacy of IAB2016 must be that this inquiry remains at the forefront of all contributions of colleagues who work in the field of bioethics. We wish the organisers of IAB2018 every success in the task of carrying forward this responsibility. 